\title{
Overlapping generations, intermediation, and the First Welfare Theorem*
}

\author{
Mark Pingle and Leigh Tesfatsion \\ University of Southern California, Los Angeles, CA 90089-0253, USA \\ Received October 1989, final version received April 1990
}

The First Welfare Theorem fails to hold for standard pure exchange overlapping generations economies because no agent exploits the profit opportunities which can arise from mediating intertemporal trade. This paper modifies the standard economy by introducing an optimizing corporate intermediary which distributes net earnings back to consumer-shareholders. The Pareto inefficient no-trade state, which is a stationary equilibrium for the standard economy, cannot be an equilibrium for this modified 'Brokerage Economy' because the intermediary perceives unbounded earnings opportunities. If the intermediary seeks to maximize the minimum dividend per share distributed over time, then there is a unique Pareto efficient stationary equilibrium for the Brokerage Economy.

\section{Introduction}

Competitive equilibrium for standard pure exchange overlapping generations economies requires consumer optimality and market clearing. As was initially shown by Samuelson (1958), the First Welfare Theorem fails to hold for this definition of competitive equilibrium.

In a broader sense, however, 'equilibrium' should represent a state in which there is no tendency for change. We take a version of Samuelson's (1958) pure exchange overlapping generations economy, referred to as the 'Samuelson Economy', and we modify it by introducing an optimizing corporate intermediary which distributes net earnings to its consumershareholders. It is shown that change will then tend to occur at what is ordinarily defined as a stationary equilibrium allocation for the Samuelson

\footnotetext{
* Preliminary versions of this paper were presented at the 1988 IMSSS Summer Workshop at Stanford University, at the 1989 Western Economic Association Meetings, at the 1989 Winter Econometric Society Meeting, and at seminars at UCLA, UC San Diego, and Iowa State University. The authors are grateful to R. Batina, W.A. Brock, D. Brown, J. Bryant, H.C. Cheng, M. Kurz, M.J.P. Magill, R. Manuelli, Y. Nyarko, M. Quinzii, E. Thompson, R. Wright, and especially to H.C. Quirmbach, M. Wooders, the editor, and three anonymous referees for helpful comments. Please address correspondence to L. Tesfatsion, Department of Economics, Iowa State University, Ames, Iowa 50011-1070.
} 
Economy if this allocation is Pareto inefficient, for the corporate intermediary will perceive unbounded earnings opportunities. Moreover, if the objective of the intermediary is to maximize the minimum dividend per share distributed over time, and the definition of competitive equilibrium is modified to include this dividend objective, then all stationary equilibria are Parcto efficient. ${ }^{1}$ Thus, when trade in the Samuelson Economy is appropriately mediated by an optimizing corporate intermediary, a welfare theorem analogous to the First Welfare Theorem is obtained.

After some historical background in section 2, the Samuelson Economy is presented and analyzed in section 3. The distinction between passive and active intermediation is clarified in section 4. In section 5 the Samuelson Economy is modified to include an active optimizing corporate intermediary. Section 5 establishes that this modified 'Brokerage Economy' has a unique stationary equilibrium, conditional on endowments and preferences, and the equilibrium is Pareto efficient. Proofs of propositions are given in the appendix.

\section{Background}

Since Adam Smith, economists have continued to develop and refine the idea that competitive market outcomes have socially optimal properties. This theme is elegantly expressed in the First Welfare Theorem, originally formulated by V. Pareto and E. Barone, which asserts that every competitive equilibrium is Pareto efficient. The regularity conditions qualifying this result are deceptively simple to state: The result holds for all Arrow-Debreu economies satisfying a weak non-satiation condition [cf. Takayama (1985, Theorem 2.C.1, p. 192)]. Thus, in the mainstream economics literature, Pareto efficiency has largely come to be regarded as a necessary characteristic of competitive equilibria.

Over 30 years ago, however, M. Allais (1947) and P. Samuelson (1958) independently formulated a dynamic framework for the study of capital and interest - the overlapping generations (OG) economy - which violates a key assumption underlying the Arrow-Debreu economy. For the latter economy, a finite number of agents and a finite number of goods are assumed to be given a priori. In contrast, the $O G$ economy is an open-ended economy incorporating birth and death, implying that the number of agents and the number of goods are both infinite.

Samuelson, in particular, investigated a pure exchange $O G$ economy with

\footnotetext{
${ }^{1}$ Pingle (1988) extends these Pareto efficiency results to non-stationary equilibria by showing that the well-known Cass-Balasko-Shell transversality condition must hold in order for the intermediary to be in equilibrium. This transversality condition is a necessary and sufficient condition for Pareto efficiency [see Cass (1972), and Balasko and Shell (1980)].
} 
identical agents and a single perishable resource. Each agent is able to borrow or lend units of the resource at a given real rate of interest. Following Arrow and Debreu, Samuelson defined a competitive equilibrium to be a sequence of real interest rates and a sequence of consumption profiles such that the lifetime utility of each consumer is maximized subject to his lifetime budget constraint, and all resource units are consumed. Surprisingly, Samuelson found that a Pareto efficient allocation was not ensured for this economy.

Samuelson's unsettling discovery has inspired numerous subsequent studies focusing entirely or in part on the inefficiency problem in OG economies. See, for example, Diamond (1965), Cass and Yaari (1966), Gale (1973), Clark (1979), Kareken and Wallace (1980), Balasko and Shell (1980), Wilson (1981), Woodford (1984), Tirole (1985), Kehoe (1986), and Aliprantis et al. (1990). The general conclusion obtained from these studies is that Pareto inefficient equilibria can be ruled out for $O G$ economies by suitably introducing a durable physical asset yielding a positive return in each period, or by introducing consumers with an effectively infinite planning horizon. However, if Samuelson's technology and preferences are retained, then only through a tax-transfer system, a continual modification of prices by means of fiat money, or some other government institution can Pareto efficiency be ensured.

In contrast, this paper suggests that the source of the inefficiency problem in the standard pure exchange $O G$ economy is that trade mediation is modelled as a passive activity. Specifically, no agent recognizes the potential profitability of organizing a corporate institution specializing in intertemporal trade mediation. ${ }^{2}$

In the Arrow-Debreu economy, the implicit modelling of trade mediation as a passive activity does not result in inefficiency. The standard story is that trades are mediated by a clearing house at competitive equilibrium prices determined by a 'Walrasian auctioneer'. The Walrasian auctioneer is a passive agent whose only concern is the coordination of demand and supply. Transforming the passive Walrasian auctioneer into an active profit-seeking agent would add nothing essential to this story. Given any competitive equilibrium, the validity of Walras' Law ensures that the value of excess supply is zero, implying that the value of the goods delivered by the Walrasian auctioneer must equal the value of the goods he receives. Thus, the Walrasian auctioneer necessarily earns zero profits.

The situation for the dynamic open-ended $O G$ economy is quite different. The value of the aggregate endowment can be infinite and Walras' Law need

\footnotetext{
${ }^{2}$ A similar point is made by E. Thompson (1967, pp. 1205-1208). He argues that overlapping generations models which generate Pareto inefficient solutions are inconsistent with the existence of a perfectly competitive market for private debt instruments.
} 
not hold [Wilson (1981)]. Moreover, an intermediary has an opportunity not available to the Walrasian auctioneer in an Arrow-Debreu economy - it can roll over debt forever. This opportunity was alluded to by Shell (1971) in his discussion of the economics of infinity. As will be shown, below, a Walrasian auctioneer dressed in a corporate business suit can extract value from an OG economy if it can persistently incur and roll over more debt than is necessary to meet current contract obligations. It is the pursuit of this value which has implications for efficiency.

\section{The Samuelson Economy}

Consider an overlapping generations economy of the type introduced by Samuelson (1958) and extended by Gale (1973), hereafter referred to as the 'Samuelson Economy'. The Samuelson Economy is a pure exchange economy which has a beginning but no end. The rate of population growth is constant and equal to zero. One consumer is born at the beginning of each period $t \geqq 1$ and is referred to as the 'generation $t$ consumer'. Each of these consumers lives for two periods, 'youth' and 'old age'. One additional consumer, the generation 0 consumer, is old when the economy begins in period 1 and dies at the end of period 1 .

Only one resource exists in the Samuelson Economy. However, letting 'good $t$ ' denote units of the resource during period $t$, the economy contains an infinite number of time-dated goods. No production technology exists for transforming good $t$ into any other good. In particular, good $t$ cannot be transformed into good $t+1$ using a storage technology, meaning that the resource is perishable.

Consumers are characterized by date of birth, endowment profiles, and preferences. Following Gale (1973), the generation 0 old consumer receives a non-negative resource endowment $w^{o}$ in period 1 together with a 'credit endowment' $A$ measured in units of good 1. If $A=0$, the generation 0 old consumer has no credit which can be traded for additional good 1, and he can only consume his resource endowment. If $A>0$, he can trade for additional good 1 and consume more than his resource endowment. If $A<0$, so that $A$ represents a debt, he must trade away a portion of his resource endowment to repay this debt. The level of satisfaction attained by the generation 0 old consumer strictly increases with increases in his consumption $c_{1}^{o}$ of good 1 .

All consumers in generations $t \geqq 1$ are identical except for date of birth. Each receives the non-negative resource endowment $w^{y}$ in youth and the non-negative resource endowment $w^{o}$ in old age, where $\left[w^{y}+w^{o}\right]>0$. For the generation $t$ consumer, young age consumption of good $t$ is denoted by $c_{t}^{y}$ and old age consumption of good $t+1$ by $c_{t+1}^{o}$. Each of these consumers has 
well-behaved consumption preferences represented by the lifetime utility function $U\left(c_{t}^{y}, c_{t+1}^{o}\right)^{3}$ The following condition is also assumed: ${ }^{4}$

$$
\operatorname{MRS}\left(w^{y}, w^{o}\right) \equiv\left[\partial U\left(w^{y}, w^{o}\right) / \partial c_{t}^{y}\right] /\left[\partial U\left(w^{y}, w^{o}\right) / \partial c_{t+1}^{o}\right]<1
$$

A sequence $\left(c_{1}^{o},\left(c_{1}^{y}, c_{2}^{0}\right),\left(c_{2}^{y}, c_{3}^{o}\right) \ldots\right)$ is an 'allocation' for the Samuelson Economy if and only if $c_{t}^{y} \geqq 0$ and $c_{t}^{o} \geqq 0$ for all $t \geqq 1$. An allocation is 'feasible' if and only if the aggregate consumption of each good is less than or equal to the aggregate endowment; that is, if and only if $c_{t}^{y}+c_{t}^{o} \leqq w^{y}+w^{o}$ for all $t \geqq 1$. A feasible allocation is 'Pareto efficient' if and only if there exists no other feasible allocation which yields at least as much lifetime utility for every consumer and strictly higher lifetime utility for at least one consumer.

Consumers in generations $t \geqq 1$ perfectly foresee prices and formulate their lifetime consumption plans at birth. The generation $t \geqq 1$ young consumer is able to borrow or lend at the one-period real interest rate $r_{t}$. Let $s_{t}$ denote the amount of young age borrowing (if $s_{i}<0$ ) or lending (if $s_{i}>0$ ). The lifetime utility-maximization problem faced by each price-taking young consumer in generation $t \geqq 1$ is

$$
\max _{\mathfrak{c}_{t}^{y} \geq 0, c_{t+1}^{o} \geqq 0, s_{t}} U\left(c_{t}^{y}, c_{t+1}^{o}\right)
$$

subject to the young and old age budget constraints

$$
\begin{aligned}
& c_{t}^{y}+s_{t}=w^{y} ; \\
& c_{t+1}^{o}=w^{o}+\left[1+r_{t}\right] s_{t} .
\end{aligned}
$$

The regularity assumptions on preferences and endowments ensure that a unique interior solution exists for problem (2) whenever the real interest rate

\footnotetext{
${ }^{3} \mathrm{By}$ well-behaved preferences, we mean $U(\cdot)$ is twice contunuously differentiable, strictly increasing, and strictly quasi-concave over the positive orthant, with $U\left(0, c_{t+1}^{a}\right)=U\left(c_{t}^{y}, 0\right)=$ $U(0,0)$.

${ }^{4}$ In Gale's (1973) terminology, an economy is 'Samuelson" ("Classical') when the marginal rate of substitution evaluated at the endowment profile is less than (greater than) one plus the rate of population growth. For an $O G$ economy with a finite beginning, Gale $(1973, \mathrm{p}$. 21) shows that the autarkic no-trade allocation $w$ in which every agent simply consumes his own endowments is a Pareto inefficient allocation if the economy is Samuelson but not if it is Classical. Condition (1) ensures that our finite-beginning economy is Samuelson, in Gale's sense; hence $w$ is a Pareto inefficient allocation. In an earlier version of this paper [Pingle and Tesfatsion (1988)], an OG economy is considered which extends over the infinite past as well as the infinite future. The notrade allocation for such an economy is Pareto inefficient for both the Classical and the Samuelson cases, and both cases are treated.
} 
$r_{t}$ exceeds -1 . Let this solution, which depends upon the interest rate $r_{t}$, be denoted by $\left(c^{y}\left(r_{t}\right), c^{o}\left(r_{t}\right), s\left(r_{t}\right)\right)$.

The consumption level attainable by the generation 0 old consumer depends upon his credit endowment $A$. Because his level of satisfaction is increasing in the consumption of good 1 , he will always consume as much good 1 as possible, meaning that his equilibrium consumption level is $c_{1}^{o}=w^{0}+A$.

Definition 1 (competitive equilibrium). ${ }^{5}$ Given a credit endowment $A$ for the generation 0 old consumer, a vector $(c, r)$, consisting of an allocation $c=\left(c_{1}^{o},\left(c_{1}^{y}, c_{2}^{o}\right),\left(c_{2}^{y}, c_{3}^{o}\right), \ldots\right)$ and a real interest rate sequence $r=\left(r_{1}, r_{2}, \ldots\right)$ is a competitive equilibrium $\boldsymbol{e}(A)$ for the Samuelson Economy if and only if:

Consumer optimization. Every generation $t \geqq 1$ young consumer solves problem (2), and the generation 0 old consumer maximizes his consumption of $\operatorname{good} 1$; i.e.,

$$
\left(c_{t}^{y}, c_{t+1}^{o}, s_{t}\right)=\left(c^{y}\left(r_{t}\right), c^{o}\left(r_{t}\right), s\left(r_{t}\right)\right) \quad \text { for all } t \geqq 1 \text {, and } c_{1}^{o}=w^{o}+A \text {. }
$$

Market clearing. The demand for good $t$ equals the supply of good $t$ for all $t \geqq 1$; i.e.

$$
c_{t}^{y}+c_{t}^{o}=w^{y}+w^{o} \quad \text { for all } t \geqq 1
$$

An equilibrium $e(A)$ is a stationary competitive equilibrium for the Samuelson Economy if and only if the real interest rate is time-invariant; i.e., if and only if there exists some constant $r$ such that $r_{t}=r$ for all $t \geqq 1$.

In any stationary competitive equilibrium, consumption profiles and savings levels are time invariant as well as the real interest rate. That is, when $r_{t}=r$ for all $t \geqq 1$, each young consumer in each generation $t \geqq 1$ solves an identical utility maximization problem; hence each chooses the same consumption profile $\left(c^{y}(r), c^{o}(r)\right)$ and the same savings level $s(r)$.

The set of credit-conditioned competitive equilibria $e(A)$ for the Samuelson Economy contains precisely two stationary competitive equilibria. To see this, first note that $A=w^{y}-c^{y}(r)$ must hold in any stationary competitive equilibrium in order for the goods market in period 1 to clear. Also, the budget constraints for problem (2) together with the goods market clearing condition (3) imply that

\footnotetext{
${ }^{5}$ Comparisons may be made with the definitions of competitive equilibrium used by Samuelson (1958, eq. 5'), Cass and Yaari (1966, p. 354), Gale (1973, p. 19), Balasko and Shell (1980, p. 285), Wilson (1981, p. 101), Woodford (1984, Section I), Yamamoto (1984, p. 14), and Kehoe (1986, Section II).
} 


$$
r\left[w^{y}-c^{y}(r)\right]=0
$$

In turn, condition (4) implies either that $r=0$, or that $r=r^{w} \equiv$ [MRS $\left.\left(w^{y}, w^{o}\right)-1\right]$, where $r^{w}$ is strictly negative by condition (1). Setting $r=r^{w}$ leads each generation $t \geqq 1$ young consumer to choose a consumption profile $\left(c^{y}, c^{o}\right)$ which coincides with his endowment profile $\left(w^{y}, w^{o}\right)$.

Using these observations, it is easily shown that one stationary equilibrium for the Samuelson Economy is the zero interest rate equilibrium $e(\hat{A})=(\hat{c}, \hat{r})$, where the allocation $\hat{c}$, real interest rate sequence $\hat{\boldsymbol{r}}$, and credit endowment $\hat{A}$ are given by

$$
\begin{aligned}
& \hat{\boldsymbol{c}}=\left(\left(w^{o}+\hat{A}\right),\left(\hat{c}^{y}, \hat{c}^{o}\right),\left(\hat{c}^{y}, \hat{c}^{o}\right) \ldots\right), \\
& \hat{\boldsymbol{r}}=(0,0, \ldots), \quad \hat{A}=\left(w^{y}-\hat{c}^{y}\right)>0 .
\end{aligned}
$$

Each consumer in generation $t \geqq 1$ consumes $\left(\hat{c}^{y}, \hat{c}^{o}\right)=\left(c^{y}(0), c^{o}(0)\right)$, and the old consumer in generation 0 consumes $c_{0}^{1}=w^{o}+\hat{A}$.

The only other stationary equilibrium is the no-trade equilibrium $e(0)=$ $\left(\boldsymbol{w}, \boldsymbol{r}^{w}\right)$, where the allocation $\boldsymbol{w}$, real interest rate sequence $\boldsymbol{r}^{\boldsymbol{w}}$, and credit endowment $A$ are given by

$$
\begin{aligned}
& \boldsymbol{w}=\left(w^{o},\left(w^{y}, w^{o}\right),\left(w^{y}, w^{o}\right), \ldots\right), \\
& \boldsymbol{r}^{\boldsymbol{w}}=\left(r^{w}, r^{w}, \ldots\right), \quad A=0 .
\end{aligned}
$$

Each consumer in generation $t \geqq 1$ consumes his endowment profile $\left(w^{y}, w^{o}\right)=$ $\left(c^{y}\left(r^{w}\right), c^{o}\left(r^{w}\right)\right)$, and the old consumer in generation 0 consumes $c_{0}^{1}=w^{o}$.

Fig. 1 depicts the consumption profiles $\left(\hat{c}^{y}, \hat{c}^{o}\right)$ and $\left(w^{y}, w^{o}\right)$ which are attained by each generation $t \geqq 1$ consumer in the stationary equilibria $e(\hat{A})$ and $e(0)$, respectively.

The allocation $\hat{\boldsymbol{c}}$ attained in the competitive equilibrium $e(\hat{A})$ is Pareto efficient. To establish this, it must be shown that there does not exist any feasible allocation which Pareto-dominates $\hat{c}$. Since a direct proof of the Pareto efficiency of $\hat{\boldsymbol{c}}$ has seemingly not been given in the literature, such a proof is provided in the appendix.

The allocation $w$ attained in the competitive equilibrium $e(0)$ is not Pareto efficient. By condition (1), the endowment profile $\left(w^{y}, w^{o}\right)$ cannot coincide with the consumption profile $\left(\hat{c}^{y}, \hat{c}^{o}\right)$ chosen by each generation $t \geqq 1$ consumer in the competitive equilibrium $e(\hat{A})$. Nevertheless, as indicated in fig. 1 , $\left(w^{y}, w^{o}\right)$ lies along the budget line faced by each generation $t \geqq 1$ consumer in the equilibrium $e(\hat{A})$. It follows that $\left(\hat{c}^{y}, \hat{c}^{o}\right)$ is strictly preferred by all consumers in generations $t \geqq 1$ to the no-trade consumption profile $\left(w^{y}, w^{o}\right)$. In addition, the generation 0 old consumer strictly prefers consuming 


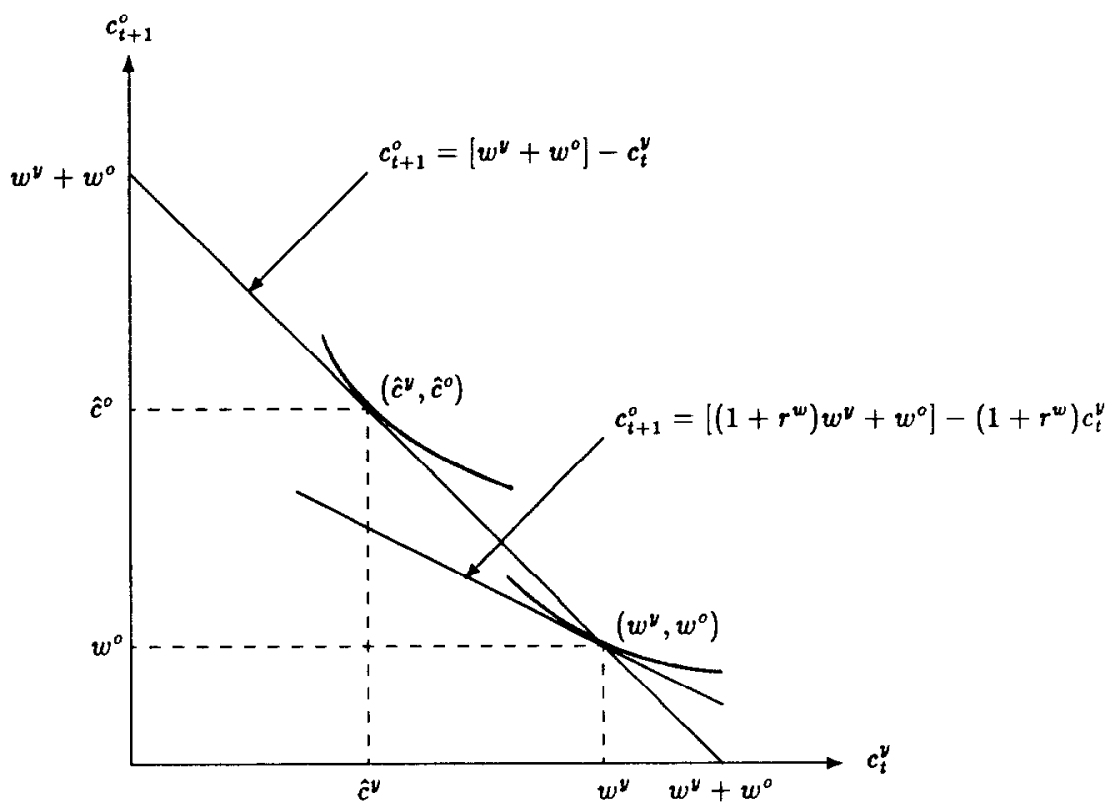

Fig. 1. Optimal consumption profiles for $r=0$ and $r=r^{w}$.

$c_{1}^{o}=w^{o}+\hat{A}$ to $c_{1}^{o}=w^{o}$. The feasible allocation $\hat{c}$ achieved in the competitive equilibrium $\boldsymbol{e}(\hat{A})$ therefore Pareto-dominates the allocation $\boldsymbol{w}$.

\section{Passive intermediation in the Samuelson Economy}

In the Samuelson Economy, there is no double coincidence of wants. A mediating institution of some kind must exist in order for trade to occur. We have assumed that consumers in the Samuelson Economy can borrow or lend. Fiat money, passed from one generation to the next, can facilitate young age lending but not young age borrowing. An intermediary which buys and sells bonds can facilitate both lending and borrowing. Thus, to be consistent with section 2, we assume that trade in the Samuelson Economy is facilitated by an intermediary which issues real bond contracts.

A young consumer in generation $t \geqq 1$ can trade young age consumption for old age consumption by trading good $t$ to the intermediary for a bond. In this case, to fulfil the bond contract struck at the interest rate $r_{t}$, the intermediary must deliver $1+r_{t}$ units of good $t+1$ to the consumer for each unit of good $t$ received. A generation $t \geqq 1$ young consumer can also trade old age consumption for young age consumption by trading a bond to the intermediary for good $t$. In this case, to fulfil the bond contract, the 
consumer must deliver $1+r_{t}$ units of good $t+1$ to the intermediary for each unit of good $t$ received. The generation 0 old consumer receives $A$ units of good 1 from the intermediary in exchange for $A$ units of credit if his credit position $A$ is non-negative. Otherwise, he delivers $-A$ units of good 1 to the intermediary to pay off his debt.

The intermediary in the Samuelson Economy is passive. The only purpose of the intermediary is to coordinate trade; it has no earnings objective. Its only choice is to decide whether or not to mediate trade. Specifically, it mediates trade if and only if supply equals demand in every market. As seen in the previous section, this passive trade mediation can result in equilibrium allocations which are not Pareto efficient.

An intermediary need not be passive. For example, it could be an earnings-driven corporation, owned by consumers, which has an objective compatible with the objectives of its consumer-shareholders. In the next section we introduce such an intermediary into the Samuelson Economy. This intermediary recognizes earnings opportunities and makes choices in pursuit of a dividend distribution objective. We show that the choices of this active intermediary can enhance economic efficiency.

\section{The Brokerage Economy}

Suppose the Samuelson Economy is modified so that trade is mediated by an optimizing corporate intermediary which distributes dividends to consumer-shareholders. Hereafter this modified economy is referred to as the 'Brokerage Economy'. In this section we first present the utility maximization problems solved by consumer-shareholders in the Brokerage Economy. We then present the optimization problem solved by the intermediary. Finally, we present a definition of equilibrium for the Brokerage Economy which incorporates the optimizing behavior of the intermediary as well as the utility-maximizing behavior of the consumer-shareholders.

\subsection{Consumers}

The ownership of the intermediary is exogenously determined. ${ }^{6}$ Maintaining the assumption that all consumers in generations $t \geqq 1$ are identical except for date of birth, each generation $t \geqq 1$ consumer owns $\theta^{y}$ shares of the intermediary when young and $\theta^{o}$ shares of the intermediary when old. Stock ownership entitles each consumer to a period $t$ dividend distribution

\footnotetext{
${ }^{6}$ There is no stock market for shares. Pingle (1988) establishes that all of the results reported. in this paper go through unchanged when a stock market for shares is introduced.
} 
corresponding to the number of shares owned. Without loss of generality, it is assumed that the number of shares which exists during a given period is normalized so that the total number of shares equals one. Thus, if the generation $t$ consumer expects the net earnings of the intermediary in period $t$ to equal $\pi_{t}^{e}$ and in period $t+1$ to equal $\pi_{t+1}^{e}$, then $\theta^{y} \pi_{t}^{e}$ and $\theta^{o} \pi_{t+1}^{e}$ are the dividends expected in periods $t$ and $t+1$.

The lifetime utility maximization problem faced by each generation $t \geqq 1$ young consumer, modified to account for expected dividends, takes the following form:

$$
\max _{c_{t}^{y} \geqq 0, c_{t+1}^{o} \geqq 0, s_{t}} U\left(c_{t}^{y}, c_{t+1}^{o}\right),
$$

subject to the young and old age budget constraints

$$
\begin{aligned}
& c_{t}^{y}+s_{t}=w^{y}+\theta^{y} \pi_{t}^{e}, \\
& c_{t+1}^{o}=w^{o}+\left[1+r_{t}\right] s_{t}+\theta^{o} \pi_{t+1}^{e} .
\end{aligned}
$$

A unique interior solution exists for problem (5) given any interest rate $r_{t}>-1$ and any non-negative expected dividend profile $D_{t}^{e}=\left(\theta^{y} \pi_{t}^{e}, \theta^{o} \pi_{t+1}^{e}\right)$. Let this solution, conditional upon $r_{t}$ and $D_{t}^{e}$, be denoted by $\left(c^{y}\left(r_{t}, D_{t}^{e}\right), c^{o}\left(r_{t}, D_{t}^{e}\right), s\left(r_{t}, D_{t}^{e}\right)\right)$.

As in the Samuelson Economy, the generation 0 old consumer in the Brokerage Economy has a credit endowment $A$. This credit endowment represents trade credits or debits held on account with the intermediary in period 1 . The generation 0 old consumer also owns $\theta^{o}$ shares of stock during period 1 which entitle him to a dividend in expected amount $D_{0}^{e}=\theta^{a} \pi_{1}^{e}$. The consumption level which the optimizing generation 0 old consumer expects to attain in period 1 is therefore given by $c_{1}^{o}=w^{o}+A+\theta^{o} \pi_{1}^{e}$.

\subsection{The intermediary}

Various subtle problems are encountered when an attempt is made to specify the behavior of the corporate intermediary. The standard approach would be to model the intermediary as a price-taking maximizer of present value profits. However, as will be clarified below, this behavioral specification is problematic. In this subsection we discuss the difficulties inherent in the modelling of price-taking corporate behavior in $O G$ economies, and we arrive at one possible optimizing behavior for a price-taking corporate intermediary which is compatible with shareholder objectives.

As a price-taker, the intermediary chooses the quantities of each good 
which it desires to mediate. The sequence $r=\left(r_{1}, r_{2}, \ldots\right)$ of real interest rates and the credit endowment $A$ are taken as given. An 'intermediation plan' is a sequence $q=\left(q_{1}, q_{2}, \ldots\right)$, where $q_{t}$ denotes the quantity of good $t$ which the intermediary chooses to receive $\left(q_{t}>0\right)$ or deliver $\left(q_{t}<0\right)$ in period $t$.

The intermediary must fulfil all contract obligations. Given the real interest rate $r_{t}$, the intermediary must return $1+r_{t}$ units of good $t+1$ to consumers during period $t+1$ for each unit of good $t$ received on contracts struck with consumers during period $t$. Alternatively, the intermediary is entitled to $1+r_{t}$ units of good $t+1$ from consumers during period $t+1$ for each unit of good $t$ delivered on contracts struck with consumers during period $t$. In period 1 , the intermediary delivers or receives $|A|$ units of good 1 to or from the generation 0 old consumer depending upon the sign of $A$. Given these contract obligations, the intermediary's 'net earnings' for period $t$ under intermediation plan $q$, conditional upon $\boldsymbol{r}$ and $A$, are given by

$$
\pi_{t}=\pi_{t}(\boldsymbol{q} ; \boldsymbol{r}, A)= \begin{cases}q_{1}-A & \text { for } t=1, \\ q_{t}-\left[1+r_{t-1}\right] q_{t-1} & \text { for } t \geqq 2 .\end{cases}
$$

For all contract obligations to be fulfilled, $\pi_{t} \geqq 0$ must hold for all $t \geqq 1$. By assumption, the intermediary distributes $\pi_{t}$ as dividends to its shareholders in each period $t \geqq 1$.

The appropriate specification of the intermediary's objective raises several questions. The first question concerns the precise meaning of 'profit'. Because financial flows are staggered, the period $t$ profit recognized by the intermediary depends upon whether the intermediary accounts for profit using 'accrual-basis accounting' or 'cash-basis accounting'.

Under accrual-basis accounting, the revenues from a particular transaction are only recognized in a profit calculation if all of the associated costs of the transaction are also recognized, and vice versa. Accrual-basis profit on any transaction made by the intermediary must equal zero, for each transaction generates a revenue which is exactly offset by a cost in present value terms. For example, if the intermediary receives $q_{t}$ units of good $\ell$ as a revenue during period $t$, the transaction also generates the period $t+1 \operatorname{cost}\left[1+r_{t}\right] q_{t}$. The value of this cost, discounted back to period $t$, is equal to $q_{t}$, the period $t$ revenue.

Under cash-basis accounting, period $t$ profit is recognized as the net value of period $t$ economic flows. Thus, the intermediary's period $t$ cash-basis profit is equal to its net earnings $\pi_{t}$ defined in (6). Period $t$ cash-basis profit is the quantity of good $t$ which the intermediary controls during period $t$ in excess of that required to fulfil all period $t$ contract obligations. In each period $t \geqq 2$ the intermediary must pay the debt $\left[1+r_{t-1}\right] q_{t-1}$ incurred in the previous period, meaning $q_{t}$ must be chosen large enough to meet this obligation. If $q_{t}$ 
is greater than $\left[1+r_{t-1}\right] q_{t-1}$, the intermediary earns a cash-basis profit in period $t$. In period $1, q_{1}$ must be chosen to meet the obligation $A$. If $q_{1}$ is greater than $A$, the intermediary earns a cash-basis profit in period 1.

Interestingly, whether or not an intermediary perceives profit opportunities depends upon how the intermediary recognizes profit. For example, an intermediary interestcd in maximizing present value accrual-basis profit would be indifferent among all feasible intermediation plans; for each such plan generates zero present value accrual-basis profit. Nevertheless, the feasible intermediation plans have different associated streams of cash-basis profits and generate different present value cash-basis profits. Thus, an intermediary which focuses on cash-basis profits (i.e., dividend distributions) would presumably not be indifferent regarding its choice of a feasible intermediation plan. To avoid confusion between accrual-basis and cashbasis profit, the term 'net earnings' will hereafter be used in place of 'cashbasis profit'.

A second question regarding the intermediary's objective concerns how the intermediary might select among intermediation plans with different associated streams of net earnings. In the absence of any quantity restrictions on the intermediation plans, a simple maximization of present value net earnings leads to the nonexistence of a 'best' plan. More precisely, given an interest rate sequence $\boldsymbol{r}$ and a non-negative constant $M$, any intermediation plan $\boldsymbol{q}$ satisfying $q_{1}>M+A$ and $q_{t}>M+\left[1+r_{t-1}\right] q_{t-1}$ for all $t \geqq 2$ yields net earnings $\pi_{t}$ which exceed $M$ in each period $t \geqq 1$. Thus, without quantity restrictions, the intermediary would perceive the possibility of obtaining arbitrarily large net earnings in each period $t \geqq 1$. A similar argument shows that a 'best' plan also fails to exist using an overtaking criterion for present value net earnings.

A third question regarding the intermediary's objective concerns the distribution of net earnings. Each shareholder cares only about the net earnings distributed during his lifetime, but the price-taking intermediary has considerable flexibility in distributing net earnings over time. How is the distribution of net earnings to be determined?

In response to these qucstions, wc assume that the price-taking intermediary behaves in the following manner. Let $Q$ denote the set of bounded sequences; i.e.,

$$
Q=\{\boldsymbol{q}: \exists a=a(\boldsymbol{q}) \text { and } b=b(\boldsymbol{q}),
$$

such that

$$
\left.-\infty<a \leqq q_{t} \leqq b<+\infty \text { for all } t \geqq 1\right\} .
$$

Given a real interest rate sequence $r$ and a credit endowment $A$, define an intermediation plan $q$ to be 'feasible' if it is an element of the set 


$$
F(\boldsymbol{r}, A)=\left\{\boldsymbol{q} \in \boldsymbol{Q}: \pi_{t}(\boldsymbol{q}, \boldsymbol{r}, A) \geqq 0 \text { for all } t \geqq 1\right\}
$$

Given $\boldsymbol{r}$ and $A$, the intermediary selects a feasible intermediation plan $\boldsymbol{q}$ to maximize the minimum dividend (net earnings) distributed per share over all periods $t \geqq 1$.

The assumption that the price-taking intermediary restricts his choice of an intermediation plan to the set $\boldsymbol{F}(\boldsymbol{r}, A)$ is rather innocuous. The aggregate endowment sequence $\left(w^{o}, w^{y}+w^{o}, w^{y}+w^{o}, \ldots\right)$ is a bounded sequence, hence only bounded intermediation plans can actually be implemented. Moreover, net earnings must be non-negative in each period in order for all contract obligations to be fulfilled. It is assumed that the intermediary is aware of these basic facts, and that he chooses to avoid intermediation plans which entail known contract default.

The assumption of a max-min dividend objective is more controversial. The objective is a variation of Rawls' (1971) max-min 'Difference Principle' applied to the distribution of dividends. Given the max-min dividend objective, the intermediary is partly an optimizer and partly a satisficer. It is an optimizer because the minimum distributable dividend is maximized. However, it is also a satisficer because it is indifferent among all intermediation plans which maximize the minimum dividend. ${ }^{7}$

Formally, the intermediary's problem takes the form

$$
\max _{\boldsymbol{q} \subset \boldsymbol{F}(\boldsymbol{r}, 1)} \inf _{t \geqq 1} \pi_{t}(\boldsymbol{q} ; \boldsymbol{r}, A)
$$

Let the (possibly empty) solution set for problem (7) be denoted by $Q(r, A)$.

\subsection{Competitive equilibrium}

A definition of competitive equilibrium ${ }^{8}$ will now be given for the Brokcrage Economy which includes the dividend objective of the intermediary as well as the utility objectives of the consumers. Let $D^{e}=\left(D_{0}^{e}, D_{1}^{e}, D_{2}^{e}, \ldots\right)$

\footnotetext{
${ }^{7}$ A series of recent studies [e.g., Kahneman et al. (1986)] have focused on situations in which fairness constraints on profit-seeking bind the outcome away from the market clearing solution. In contrast, the current paper shows that a fairness proviso (maximize the minimurn distributed dividend per share) can act as an aid to the achievement of a Pareto efficient market clearing outcome. This is surprising, since under this conservative max-min dividend policy the intermediary is indifferent among all Pareto-improvements which do not specifically benefit the worst-off shareholder.

${ }^{8}$ Some may object to the use of the term 'competitive' here, since the intermediary is not a profit maximizer in the usual sense. However, we retain this term to indicate that the intermediary is still assumed to be a price-taker with no direct influence on market prices.
} 
denote the sequence of expected dividend profiles for consumers in generations $t \geqq 0$.

Definition 2. Given a credit endowment $A$ for the generation 0 old consumer, a vector $\left(\boldsymbol{c}, \boldsymbol{D}^{\boldsymbol{e}}, \boldsymbol{q}, \boldsymbol{r}\right)$ consisting of an allocation $\boldsymbol{c}$, an expected dividend sequence $D^{e}$, an intermediation plan $q$, and a real interest rate sequence $r$ with $r_{t}>-1$ for all $t \geqq 1$ is a competitive equilibrium $e^{B}(A)$ for the Brokerage Economy if and only if:

Consumer optimization. Every generation $t \geqq 1$ young consumer solves problem (5), and the generation 0 old consumer maximizes his consumption of good 1; i.e.,

$$
\left(c_{t}^{y}, c_{t+1}^{o}, s_{t}\right)=\left(c^{y}\left(r_{t}, D_{t}^{e}\right), c^{o}\left(r_{t}, D_{t}^{e}\right), s\left(r_{t}, D_{t}^{e}\right)\right) \quad \text { for all } t \geqq 1
$$

and

$$
c_{1}^{o}=w^{o}+A+D_{0}^{e}
$$

Intermediary optimization. The intermediary solves problem (7); i.e., $q \in Q(r, A)$.

Product market clearing. In each period $t$ the demand for good $t$ equals the supply of good $t$; i.e.,

$$
c_{t}^{y}+c_{t}^{o}=w^{y}+w^{o} \text { for all } t \geqq 1 .
$$

Bond market clearing. In each period $t$ the demand for real bonds equals the supply of real bonds; i.e., $q_{t}=s_{t}$ for all $t \geqq 1$, and the intermediary delivers (receives) $|A|$ units of good 1 to (from) the gencration 0 old consumer if $A \geqq(<) 0$.

Expectations fulfilled. Expected dividend distributions coincide with actual dividend distributions in each period $t$; i.e., $D_{t}^{e}=\left(\theta^{y} \pi_{t}, \theta^{o} \pi_{t+1}\right)$ for all $t \geqq 1$, and $D_{0}^{e}=\theta^{o} \pi_{1}$.

An equilibrium $e^{B}(A)$ is a stationary competitive equilibrium for the Brokerage Economy if and only if the real interest rate and dividend expectations are time-invariant; i.e., if and only if there exist values $r$ and $\pi^{e}$ such that $r_{t}=r$ and $\pi_{t}^{e}=\pi^{e}$ for all $t \geqq 1$.

\section{Active intermediation and Pareto efficiency}

In the Samuelson Economy, all consumers must be able to actualize their optimal consumption plans in order for the economy to be in equilibrium. In the Brokerage Economy, the intermediary must be able to actualize its optimal intermediation plan as well. In this section we establish some 
important links between active earnings-driven intermediation and Pareto efficiency. Proofs are given in the appendix.

Proposition 1. The endowment allocation $\boldsymbol{w}$ cannot be supported as a competitive equilibrium allocation for the Brokerage Economy.

Proposition 1 reveals a crucial difference between the Samuelson Economy and the Brokerage Economy. The Pareto inefficient endowment allocation is a competitive equilibrium allocation for the former economy, but not for the latter. The reason is that the intermediary in the Brokerage Economy perceives unbounded opportunities to increase its net earnings in each period $t \geqq 1$ when faced with the interest rate $r^{w}$ which leads each generation $t \geqq 1$ young consumer to choose the no-trade consumption profile $\left(w^{y}, w^{o}\right)$. Consequently, an immediate corollary to Proposition 1 is that the endowment allocation fails to be a competitive equilibrium allocation for the Brokerage Economy under any reasonable specification of an earnings objective for the intermediary.

The next result shows that the particular earnings objective assumed for the intermediary in section 4.2 places a strong restriction on the set of potential stationary equilibrium interest rates.

Proposition 2. Given a credit endowment A for the generation 0 old consumer, and a stationary real interest rate $r>-1, a$ solution exists for the intermediary's problem (7) if and only if $r=0$.

Using Proposition 2, the following analog to a First Welfare Theorem is obtained for the Brokerage Economy.

Proposition 3. There exists a unique stationary competitive equilibrium for the Brokerage Economy, and the associated allocation is Pareto efficient.

Specifically, the consumption allocation attained by consumers in the unique stationary brokerage competilive equilibrium coincides with the Pareto efficient consumption allocation $\hat{c}$ attained by consumers in the competitive equilibrium $e(0)$ for the Samuelson Economy. The equilibrium real interest rate for this unique stationary brokerage competitive equilibrium is $r=0$, and all equilibrium dividend distributions equal zero.

In summary, introducing an optimizing corporate intermediary into the Samuelson Economy has resulted in a narrowing down of the set of possible stationary equilibrium allocations. The Pareto inefficient no-trade allocation $\boldsymbol{w}$ is no longer viablc; only the Pareto efficient allocation $\hat{c}$ remains. An intuitive understanding of this finding is suggested by the following comparison: The exclusion of an optimizing corporate intermediary in the Samuelson 
Economy has the same effect on the set of stationary equilibrium allocations as the exclusion of an optimizing firm in a Robinson Crusoe economy with a storage technology.

In the traditional Robinson Crusoe story of Koopmans (1957, Section 1), the durable resource endowment $w^{y}$ of young Robinson at time $t$ can be transformed by storage into consumption good for old Robinson at time $t+1$; and an optimizing firm is inserted between young Robinson and old Robinson to embody this intertemporal 'production' possibility. Competitive equilibrium is then defined in terms of conditions guaranteeing lifetime utility-maximization for Robinson, profit-maximization for the firm, and market clearing.

Suppose, instead, that competitive equilibrium is defined for the Robinson Crusoe economy in the same way that Definition 1 defines competitive equilibrium for the Samuelson Economy. That is, suppose that Robinson's ability to store resource units from one period to the next on a one-for-one basis is ignored, and that competitive equilibrium is defined solely in terms of lifetime utility maximization for Robinson, conditional on a given real interest rate $r$, together with a market clearing condition. Fig. 1, which depicts the existence of a Pareto-inferior competitive equilibrium consumption profile $\left(w^{y}, w^{o}\right)$ for consumers in the Samuelson Economy, would then likewise depict the existence of a Pareto-inferior competitive equilibrium consumption profile $\left(w^{y}, w^{o}\right)$ for Robinson Crusoe. Since the Robinson Crusoe economy satisfies all of the assumptions of the First Welfare Theorem, this is absurd.

The obvious difficulty is that the definition of competitive equilibrium for the Robinson Crusoe economy is incomplete without explicit recognition of storage as a utility-enhancing activity which must be optimally exploited. Without recognizing storage, the only way Robinson is allowed to transfer resource units from youth to old age is by saving at some given interest rate $r$. However, at the particular interest rate $r^{w}<0$ which supports the consumption profile $\left(w^{y}, w^{o}\right)$, the Robinson Crusoe firm would perceive unbounded profit opportunities.

We argue, in similar terms, that any definition of 'equilibrium' for the Samuelson Economy is incomplete without explicit recognition of trade mediation as a utility-enhancing activity which must be optimally exploited. In the Brokerage Economy, the intermediary is modelled as an optimizing corporate institution with a dividend objective. This modification of the Samuelson Economy results in an efficiency proposition (Proposition 3) which is analogous to the standard First Welfare Theorem.

Of course, a reasonable question to ask is: "Can corporate intermediaries exist as purely private institutions?'. The intermediary in the Brokerage Economy is assumed to be an unregulated institution which is not threatened by entry. More realistically, intermediaries should be allowed to enter and 
exit the economy in an endogenously determined manner; but this entry and exit may well have to be subject to various types of legal restrictions (e.g., regulations for the protection of depositors against bankruptcies) in order for private agents to have an incentive to organize and maintain intermediaries. Such regulations are routinely imposed on banks and other intermediaries in actual market economies.

In addition, price-taking is surely an unrealistic behavioral specification for many of the major banking and brokerage institutions which actually engage in trade mediation activities. We anticipate that a relaxation of this assumption will permit a more realistic and interesting model of the intermediation sector.

While there are many concerns yet to be clarified, our results suggest that careful consideration must be given to the modelling of intermediation in dynamic open-ended economies.

\section{Appendix}

\section{A. Proof of Pareto efficiency of the allocation $\hat{\boldsymbol{c}}$}

Given the time-invariant interest rate $\hat{r}=0$, the lifetime utility maximization problem (2) faced by each generation $t \geqq 1$ young consumer reduces to

$$
\max _{c_{t}^{y} \geqq 0, c_{t+1}^{o} \geqq 0} U\left(c_{t}^{y}, c_{t+1}^{o}\right)
$$

subject to

$$
c_{t}^{y}+c_{t+1}^{o}=w^{y}+w^{o} .
$$

Letting $\left(\hat{c}^{y}, \hat{c}^{o}\right)$ denote the unique solution to problem (A.1), the stationary competitive equilibrium with $\hat{A}=w^{y}-\hat{c}^{y}$ is given by $e(\hat{A})=(\hat{c}, \hat{\boldsymbol{r}})$, where $\hat{\boldsymbol{c}}=\left(w^{o}+\hat{A},\left(\hat{c}^{y}, \hat{c}^{o}\right),\left(\hat{c}^{y}, \hat{c}^{o}\right), \ldots\right)$ and $\hat{\boldsymbol{r}}=(0,0, \ldots)$.

Because it is an equilibrium allocation, the allocation $\hat{c}$ is feasible. Suppose there exists some other feasible allocation

$$
c=\left(w^{o}+A,\left(c_{1}^{y}, c_{2}^{o}\right),\left(c_{2}^{y}, c_{3}^{o}\right), \ldots\right),
$$

with $A=w^{y}-c_{1}^{y}$ which Pareto-dominates the allocation $\hat{c}$. Without loss of generality, it can be assumed that $c$ is efficient. It follows from these suppositions that $c$ satisfies

$$
\begin{aligned}
& U\left(c_{t}^{y}, c_{t+1}^{o}\right) \geqq U\left(\hat{c}^{y}, \hat{c}^{o}\right) \text { for all periods } t \geqq 1, \\
& A \geqq \hat{A},
\end{aligned}
$$


and

$$
c_{t}^{y}+c_{t}^{o}=w^{y}+w^{o}=\hat{c}^{y}+\hat{c}^{o} \quad \text { for all periods } t \geqq 1 .
$$

In addition, either

$$
U\left(c_{s}^{y}, c_{s+1}^{o}\right)>U\left(\hat{c}^{y}, \hat{c}^{o}\right) \text { for some period } s \geqq 1 \text {, }
$$

or

$$
A>\hat{A} \text {. }
$$

Because the solution $\left(\hat{c}^{y}, \hat{c}^{o}\right)$ for problem (A.1) is unique, condition (A.3) implies that, for each period $t \geqq 1$, either

$$
c_{t}^{y}+c_{t+1}^{o}>w^{y}+w^{o}=\hat{c}^{y}+\hat{c}^{o}
$$

or

$$
c_{i}^{y}=\hat{c}^{y} \quad \text { and } \quad c_{t+1}^{o}=\hat{c}^{o}
$$

If condition (A.9) holds for all $t \geqq 1$, then neither condition (A.6) nor condition (A.7) could hold. Therefore, condition (A.8) must hold for at least one period $t$, say $t=k$.

Suppose $c_{k}^{y}>\hat{c}^{y}$. Then, using (A.3) and (A.5), $c_{t}^{y}>\hat{c}^{y}$ and $c_{t}^{o}<\hat{c}^{o}$ for all $t \leqq k$. In particular, $c_{1}^{y}>\hat{c}^{y}$, meaning $A<\hat{A}$; but this contradicts condition (A.4).

Suppose instead that $c_{k}^{y} \leqq \hat{c}^{y}$. Condition (A.8) then implies $c_{k+1}^{o}>\hat{c}^{o}$. Using (A.3) and (A.5), it follows that $c_{t}^{y}<\hat{c}^{y}$ and $c_{t+1}^{o}>\hat{c}^{o}$ for all $t \geqq k+1$, meaning condition (A.8) holds for all $t \geqq k$. It then follows from (A.5) and (A.8) that $c_{t}^{o}$ is a strictly increasing function of $t$ for $t \geqq k$ with its range contained in the compact interval $\left[0, w^{y}+w^{o}\right]$, and $c_{t}^{y}$ is a strictly decreasing function of $t$ for $t \geqq k$ with its range contained in the compact interval $\left[0, w^{y}+w^{o}\right]$. Consequently, by the monotone convergence theorem, there exists a consumption profile $\left(c^{y}, c^{o}\right)$ satisfying $w^{y}+w^{o} \geqq \hat{c}^{y}>c^{y} \geqq 0$ and $w^{y}+w^{o} \geqq c^{o}>\hat{c}^{o} \geqq 0$ such that

$$
\lim _{t \rightarrow+\infty} c_{t}^{y}=c^{y}
$$

and

$$
\lim _{t \rightarrow+\infty} c_{t}^{o}=c^{o}
$$

By (A.3) and (A.5), the limiting consumption profile $\left(c^{y}, c^{o}\right)$ is feasible and yields at least as much utility as $\left(\hat{c}^{y}, \hat{c}^{o}\right)$, a contradiction of the uniqueness of the solution to problem (A.1). 
It follows that no feasible allocation Pareto-dominates $\hat{c}$. Hence, the allocation $\hat{c}$ is Pareto efficient.

\section{A.2. Proofs for propositions of section 5}

Proposition 1. The endowment allocation $w$ cannot be supported as a competitive equilibrium allocation for the Brokerage Economy.

Proof. For the endowment allocation $w$ to be a competitive equilibrium allocation for the Brokerage Economy, it is necessary to have $r_{t}=r^{w}$ in each period $t \geq 1$. Otherwise, the optimizing young consumers in periods $t \geqq 1$ would not choose to consume their endowment profiles. By condition (1), $r^{w}$ satisfies $-1<r^{w}<0$. Faced with such an interest rate in each period $t$, the intermediary perceives unbounded opportunities to increase its net earnings in each period $t \geqq 1$ by mediating an arbitrarily large amount of trade - see the proof of Proposition 2, below, for details. Consequently, the intermediary's optimization problem (7) has no solution.

Proposition 2. Given a credit endowment $A$ for the generation 0 old consumer, and a stationary interest rate $r>-1$, a solution exists for the intermediary's problem (7) if and only if $r=0$.

Proof (necessity). Define $\boldsymbol{r}=(r, r, \ldots)$ and

$$
S_{t}=\left[1+(1+r)+(1+r)^{2}+\ldots+(1+r)^{t-1}\right] \text { for all } t \geqq 1 .
$$

Suppose $-1<r<0$. Consider the intermediation plan $q$ given by

$$
q_{t}=[M+A] S_{t} \text { for all } t \geqq 1,
$$

where $M$ is any non-negative constant satisfying $0 \leqq[M+A]<+\infty$. Since $S_{t}$ converges to a finite limit, so does $q_{t}$, implying that the sequence $q$ is an element of the set $Q$ of bounded sequences. Bccause it is a bounded sequence, and yields $\pi_{1}(\boldsymbol{q} ; \boldsymbol{r}, A)=M \geqq 0$ and $\pi_{t}[\boldsymbol{q} ; \boldsymbol{r}, A]=[M+A] \geqq 0$ for all $t \geqq 2$, the intermediation plan $\boldsymbol{q}$ is an element of the feasible set $\boldsymbol{F}(\boldsymbol{r}, A)$. Since $M$ can be chosen arbitrarily large, it follows that no solution exists for the intermediary's problem (7).

Suppose $r>0$. For an intermediation plan $q$ to be feasible, $\pi_{t}(\boldsymbol{q} ; \boldsymbol{r}, A) \geq 0$ must hold for all $t \geqq 1$. This implies $q_{t} \geqq[1+r]^{t-1} A$ for all $t \geqq 1$. However, $r>0$ implies that $q_{t}$ diverges; i.e., the intermediation plan $q$ is unbounded. Thus, no feasible intermediation plan exists if $r>0$.

Proof (sufficiency). Suppose $r=0$, and let $M$ denote any non-negative 
constant. In order for an intermediation plan $\boldsymbol{q}$ to satisfy $\pi_{t}(\boldsymbol{q} ; \boldsymbol{r}, A) \geqq M$ for all $t \geqq 1$, it must hold that $q_{1} \geqq[M+A]$ and

$$
q_{t+1} \geqq S_{t} M+[1+r]^{t} q_{1} \text { for all } t \geqq 1 \text {, }
$$

where $S_{t}$ is defined as in (A.12). Since $S_{t}$ diverges for $r=0$, the intermediation plan $q$ is a bounded sequence, and hence feasible, only if $M=0$. It follows that zero is the greatest lower bound for the per share net earnings which the intermediary can feasibly distribute in each period $t \geqq 1$, and the intermediary is indifferent among all feasible intermediation plans which distribute at least zero net earnings per share in each period $t \geqq 1$. One such feasible plan is the sequence $q$ given by $q_{t}=A$ for all $t \geqq 1$. The solution set $Q(r, A)$ for the intermediary's optimization problem (7) is therefore non-empty when $r=0$.

Proposition 3. There exists a unique stationary competitive equilibrium for the Brokerage Economy, and the associated allocation is Pareto efficient.

Proof. By Proposition 2, given any stationary real interest rate $r>-1$, a solution exists for the intermediary's problem (7) if and only if $r=0$. Moreover, given a stationary real interest rate $r=0$, the intermediary is indifferent among all feasible intermediation plans yielding at least zero net earnings $\pi_{t}$ in each period $t$.

Suppose $e^{B}(A)=\left(c, D^{e}, \boldsymbol{q}, \boldsymbol{r}\right)$ is a stationary competitive equilibrium for the Brokerage Economy with a stationary real interest rate $r=0$. In order for the stationary expectations of consumers to be fulfilled, $\pi_{t}=\pi^{e}$ must hold for all $t \geqq 1$. For the intermediation plan to be feasible, it follows from the proof for Proposition 2 that the intermediary cannot distribute a time invariant dividend greater than zero and must distribute a dividend of at least zero for all $t \geqq 1$. Thus, for the expectations of consumers to be actualized, $\pi_{t}=\pi^{e}=0$ must hold for all $t \geqq 1$.

When each generation $t \geqq 1$ consumer is faced with the real interest rate $r=0$ and expects $\pi^{e}=0$, cach chooses the consumption profile $\left(\hat{c}^{y}, \hat{c}^{o}\right)$ [see fig. 1]. The product market clearing condition (8) therefore holds for all $t \geqq 2$. Moreover, bond market clearing implies that the intermediary receives $\hat{q}_{t}=w^{y}-\hat{c}^{y}$ from the generation $t$ young consumer and delivers $\hat{q}_{t-1}=w^{y}-\hat{c}^{y}$ to the generation $t-1$ old consumer in each period $t \geqq 2$. In period 1 the intermediary receives $\hat{q}_{1}=w^{y}-\hat{c}^{y}$ from the young consumer and must deliver $A$ to the old consumer. Thus, period 1 net earnings for the intermediary are zero if and only if $A=\hat{A} \equiv\left[w^{y}-\hat{c}^{y}\right]$. Given $A=\hat{A}$, the consumption $c_{1}^{o}$ of the generation 0 old agent is given by $c_{1}^{o}=w^{o}+\left[w^{y}-\hat{c}^{y}\right]=\hat{c}^{o}$; hence the product market clearing condition (8) also holds for period 1.

It follows from these observations that the Brokerage Economy has a 
unique stationary equilibrium given by $\boldsymbol{e}^{B}(\hat{A})=(\hat{\boldsymbol{c}}, \hat{\boldsymbol{D}}, \hat{\boldsymbol{q}}, \hat{\boldsymbol{r}})$, where $\hat{A}=$ $\left[w^{y}-\hat{c}^{y}\right], \hat{\boldsymbol{c}}=\left(\hat{c}^{o},\left(\hat{c}^{y}, \hat{c}^{o}\right), \ldots\right)$ is the Pareto efficient allocation discussed in section $2, \hat{D}^{e}$ is the sequence of expected dividend profiles with all expected dividends equalling zero, $\hat{q}$ is the feasible intermediation plan given by $\hat{q}_{t}=\hat{A}$ for all $t \geqq 1$, and $\hat{r}$ is the sequence of real interest rates all equalling zero.

\section{References}

Aliprantis, C.D., D.J. Brown and O. Burkinshaw, 1990, Valuation and optimality in exchange economies with a countable number of agents, International Economic Review 31, 275-288.

Allais, M., 1947, Economie et interet (Imprimerie Nationale, Paris).

Balasko, Y. and K. Shell, 1980, The overlapping generations model, I: The case of pure exchange without money, Journal of Economic Theory 23, 281--306.

Cass, D., 1972, On capital overaccumulation in the aggregative neoclassical model of economic growth: A complete characterization, Journal of Economic Theory 4, 200-223.

Cass, D. and M. Yaari, 1966, A re-examination of the pure consumption loan model, Journal of Political Economy 74, 353-367.

Clarke, S.A., 1979, Pareto-optimality in the pure distribution economy with an infinite number of consumers and commodities, Journal of Economic Theory 21, 336-347.

Diamond, P., 1965, National debt in a neoclassical growth model, American Economic Review $55,1126-1150$

Gale, D., 1973, Pure exchange equilibrium of dynamic economic models, Journal of Economic Theory 6, 12-36.

Kahneman, D., J. Knetsch and R. Thaler, 1986, Fairness as a constraint on profit seeking: Entitlements in the market, American Economic Review 76, 728-741.

Kareken, J.H. and N. Wallace, 1980, Models of monetary economies (Federal Reserve Bank, Minneapolis, MN).

Kehoe, T., 1986, General equilibrium models with infinite numbers of agents and goods, Unpublished manuscript (Clare College, Cambridge).

Koopmans, T.C., 1957, Allocation of resources and the price system, Essay 1 in: Three essays on the state of economic science (McGraw-Hill, New York).

Pingle, M., 1988, The brokerage function and pareto-efficiency in an overlapping generations economy, Dissertation (University of Southern California, Los Angeles, CA).

Pingle, M. and L. Tesfatsion, 1988, Overlapping generations and the First Welfare Theorem, Modelling Research Group Working paper no. 8823 (Department of Economics, University of Southern California, CA), revised November 1989.

Rawls, J., 1971, A theory of justice (Harvard University Press, Cambridge, MA).

Samuelson, P., 1958, An exact consumption loan model of interest with or without the social contrivance of money, Journal of Political Economy 66, 467-482.

Shell, K., 1971, Notes on the cconomics of infinity, Journal of Political Economy 79, 1002-1011.

Takayama, A., 1985, Mathematical economics (Cambridge University Press).

Thompson, E., 1967, Debt instruments in both macroeconomic theory and capital theory, American Economic Review 57, 1196-1209.

Tirole, J., 1985, Asset bubbles and overlapping generations, Econometrica 53, 1499-1528.

Wilson, C., 1981, Equilibrium in dynamic models with an infinity of agents, Journal of Economic Theory 24, 95-111.

Woodford, M., 1984, Indeterminacy of equilibrium in the overlapping generations model: A survey, Unpublished manuscript (IMSSS, Stanford University, Stanford, CA).

Yamamoto, K., 1984, A characterization of Pareto efficient allocations in the overlappinggenerations model of exchange economy, Unpublished manuscript (State University of New York al Buffalu, Buffalo, NY). 